\title{
Discharge coefficient of a rectangular sharp-edged broad-crested weir
}

\author{
Zbyněk Zachoval $^{1 *}$, Michaela Knéblová ${ }^{2}$, Ladislav Roušar ${ }^{3}, J_{a ́ n}$ Rumann ${ }^{4}$, Jan Šulc ${ }^{1}$ \\ ${ }^{1}$ Laboratory of Water Management Research, Department of Water Structures, Faculty of Civil Engineering, Brno University of Technolo- \\ gy, Veveř́ 331/95, 602 00, Brno, Czech Republic. E-mail: sulc.j@fce.vutbr.cz (Jan Šulc) \\ ${ }_{2}^{2}$ Department of Water management Conceptions and Information, Odra River Board, Varenská 49, 701 26, Ostrava, Czech Republic. E- \\ mail: kneblova.michaela@gmail.com \\ ${ }^{3}$ Department of Water Structures, Faculty of Civil Engineering, Brno University of Technology, Veveři 331/95, 602 00, Brno, Czech Re- \\ public. E-mail: rousar.1@fce.vutbr.cz \\ ${ }^{4}$ Department of Hydraulic Engineering, Faculty of Civil Engineering, Slovak University of Technology in Bratislava, Radlinského 11,813 \\ 68, Bratislava, Slovak Republic. E-mail: jan.rumann@stuba.sk \\ ${ }^{*}$ Corresponding author. E-mail: zachoval.z@fce.vutbr.cz
}

\begin{abstract}
This paper is concerned with the determination of the relationship for the calculation of the discharge coefficient at free overflow over a rectangular sharp-edged broad-crested weir without lateral contraction. The determination was made on the basis of new measurement in a range of the relative thickness of the weir from 0.12 to 0.30 and newly in a large range of relative height of the weir extremely from 0.24 to 6.8 which greatly expands the application possibilities of low weirs. In addition, the effects of friction and surface tension on the value of the discharge coefficient were evaluated as well as the effect of the relative thickness of the weir. The new equation for discharge coefficient, expressed using the relative height of the weir, was subjected to verification made by an independent laboratory which confirmed its accuracy.
\end{abstract}

Keywords: Broad-crested weir; Discharge coefficient; Relative height of weir.

\section{INTRODUCTION}

Rectangular weirs with finite crest width (Govinda Rao and Muralidhar, 1963) (finite weir thickness or length) are often used for the determination of discharge (ISO 3846, 2008). Weirs are divided according to their relative thickness $h / t$, where $h[\mathrm{~m}]$ is the overflow head and $t[\mathrm{~m}]$ is the thickness of the weir (the length in the direction of flow) into (Govinda Rao and Muralidhar, 1963) short-crested, broad-crested and longcrested weirs. The weir crest is horizontal; the upstream and downstream walls are vertical. The upstream and downstream edges of the weir crest are either sharp or rounded. Weirs are placed either into a rectangular channel with the same width $B[\mathrm{~m}]$ as the weir $b[\mathrm{~m}]$, hence they are without lateral contraction or they are with lateral contraction.

The discharge coefficient is constant in relatively high rectangular sharp-edged weirs with a broad crest and without lateral contraction $0.1 \leq h / t \leq 0.3$ and $h / P<0.15$ (ISO 3846, 2008), where $P[\mathrm{~m}]$ is the height of the weir. In relatively low ones, it is the function of the relative height $h / P$ (Bos, 1989). Close to the upper limit of the definition of weirs with a broad crest (ISO 3846, 2008) the discharge coefficient is also the function of the relative thickness $h / t$ of the weir (Singer, 1964).

The functional relationship between the discharge coefficient $C_{d}$ [-] based on energy head $H[\mathrm{~m}]$ and the relative height of the weir $h / P$ is not known (Fig. 1 and 2) for high values $h / P>3.5$ in range $0.08 \leq h / t \leq 0.3$ and the measured data in range $1.2<h / P<3.5$ are extensively scattered; hence a detailed investigation was carried out for its determination.

\section{BRIEF OVERVIEW OF RESEARCH PERFORMED}

A great number of authors have been concerned with determining the discharge coefficient of rectangular sharp-edged broad-crested weirs. In Table 1 are particularly enumerated those authors (and their dataset) who published measured data in a range $0.08 \leq h / t \leq 0.40$.

For determining the discharge coefficient $C[-]$ based on head $h$, ISO 3846 (2008) gives a table and an area chart in relationship to $h / t$ and $h / P$. It determines the constant value of the discharge coefficient at $C=0.85$ in ranges of $0.1 \leq h / t \leq 0.3$ and $h / P<0.15$. The relationship of discharge coefficient $C_{d}$ calculated according to the standard in a range of $0.1 \leq h / t \leq 0.3$ is shown in Fig. 2.

From all measured data (Table 1) were selected data fulfilling range $0.08 \leq h / t \leq 0.30, h \geq 0.06 \mathrm{~m}, b \geq 0.30 \mathrm{~m}$, where is assumed correlation only on the relative height $h / P$ of weir. Selected data and recommended limits by ISO 3846 (2008) are given in Fig. 1 and discharge coefficient $C_{d}$ in relationship to $h / P$ is in Fig. 2 for the purposes of mutual comparison.

\section{THEORETICAL BASIS}

The discharge $Q\left[\mathrm{~m}^{3} \cdot \mathrm{s}^{-1}\right]$ of broad-crested weir with a rectangular cross section and without the influence of the tailwater level (Harrison, 1967) is determined by (Bos, 1989)

$Q=\left(\frac{2}{3}\right)^{3 / 2} C_{d} g^{1 / 2} b H^{3 / 2}$,

where $g\left[\mathrm{~m} \cdot \mathrm{s}^{-2}\right]$ is gravitational acceleration; $b[\mathrm{~m}]$ is the width of the weir and $H[\mathrm{~m}]$ is the energy overflow head. In practical applications, in which it is necessary that measurable quantities be included in the Eq. (1), the energy overflow head $H=h+Q^{2} /\left[2 g b^{2}(h+P)^{2}\right]$ substitutes the overflow head $h$. This is made by introducing the coefficient of approach velocity $C_{v}=(H / h)^{3 / 2}[-]$, then the Eq. (1) is

$$
Q=\left(\frac{2}{3}\right)^{3 / 2} C_{v} C_{d} g^{1 / 2} b h^{3 / 2}
$$


As the coefficient of approach velocity $C_{v}$ is, among others, also a function of the relative height $h / P$ of the weir, it is expressed by a discharge coefficient $C=C_{v} C_{d}$.

According to dimensional analysis, the discharge coefficient $C$ is a function of (Tracy, 1957)

$C=\mathrm{f}\left\{\mathrm{Re}, \mathrm{We}, \frac{h}{b}, \frac{h}{P}, \frac{h}{t}, \frac{h}{k}\right\}$,

where $k[\mathrm{~m}]$ is the Nikuradse's equivalent sand-grain roughness height.

Table 1. Summary of the experimental studies of sharp-edged broad-crested weirs.

\begin{tabular}{|c|c|c|c|c|}
\hline Investigator & $\begin{array}{l}\text { Overflow } \\
\text { head } \\
h[\mathrm{~m}]\end{array}$ & $\begin{array}{c}\begin{array}{c}\text { Weir } \\
\text { thickness }\end{array} \\
t[\mathrm{~m}]\end{array}$ & $\begin{array}{l}\text { Weir } \\
\text { height } \\
P[\mathrm{~m}]\end{array}$ & $\begin{array}{l}\text { Weir } \\
\text { width } \\
b[\mathrm{~m}]\end{array}$ \\
\hline $\begin{array}{l}\text { Bazin, } 1896 \text { (Horton, 1907) } \\
(113,114,115)\end{array}$ & $0.055-0.447$ & $0.10-2.00$ & 0.75 & 2.00 \\
\hline $\begin{array}{l}\text { U. S. Geological Survey, } \\
1903 \text { (Horton, 1907) }(41 \text {, } \\
42,43,44,45,46,47)\end{array}$ & $0.023-1.351$ & $0.28-4.97$ & 3.43 & 4.87 \\
\hline Woodburn, 1932 & $0.155-0.429$ & 3.5 & 0.53 & 0.61 \\
\hline $\begin{array}{l}\text { Prentice, } 1935 \text { (Stevens et } \\
\text { al., 1941) }\end{array}$ & $0.030-0.183$ & $0.61-0.91$ & 0.20 & 0.30 \\
\hline $\begin{array}{l}\text { Doeringsfeld and Barker, } \\
1941\end{array}$ & $0.016-0.179$ & $0.34-0.69$ & $0.08-0.16$ & $0.25-0.51$ \\
\hline Tison, 1950 & $0.044-0.165$ & 1.80 & 0.30 & 0.50 \\
\hline $\begin{array}{l}\text { Berezinskij, } 1950 \text { (6a, 8, 9, } \\
9 a, 11,16,17)\end{array}$ & $0.045-0.358$ & $0.39-2.50$ & $0.03-0.46$ & $0.51-1.92$ \\
\hline $\begin{array}{l}\text { Govinda Rao and Murali- } \\
\text { dhar, } 1963\end{array}$ & $0.031-0.277$ & $0.10-3.05$ & $0.30-0.31$ & 0.61 \\
\hline $\begin{array}{l}\text { Wakhlu, } 1963 \text { (Shaw et al., } \\
\text { 1972) }\end{array}$ & $0.012-0.083$ & 0.31 & 0.05 & 0.20 \\
\hline Singer, 1964 & $0.067-0.380$ & $0.91-1.37$ & $0.20-0.25$ & $0.44-0.76$ \\
\hline Shukla, 1970 & $0.102-0.121$ & $1.27-1.52$ & $0.02-0.13$ & 0.46 \\
\hline Moss, 1972 & $0.033-0.076$ & $0.15-0.76$ & 0.152 & 0.61 \\
\hline Crabbe, 1974 & $0.06-0.37$ & $0.08-0.12$ & 0.15 & 0.3 \\
\hline $\begin{array}{l}\text { Sreetharan, } 1983(4 \mathrm{~B}, 7 \mathrm{~A} \\
7 \mathrm{~B}, 8 \mathrm{~A}, 8 \mathrm{~B}, 9 \mathrm{~A}, 10 \mathrm{~A}, 10 \mathrm{~B}, \\
11 \mathrm{~A}, 11 \mathrm{~B}, 12 \mathrm{~B})\end{array}$ & $0.037-0.290$ & $0.08-0.90$ & $0.08-0.20$ & $0.27-0.51$ \\
\hline Tim, 1986 & $0.025-0.122$ & 0.31 & 0.10 & 0.25 \\
\hline Hager and Schwalt, 1994 & $0.027-0.202$ & 0.50 & 0.40 & 0.50 \\
\hline Johnson, 2000 & & $0.02-0.61$ & $0.05-0.61$ & $0.91-1.83$ \\
\hline Zachoval et al., 2012a & $0.036-0.191$ & 0.50 & 0.25 & 1.00 \\
\hline Goodarzi et al., 2012 & $0.115-0.195$ & 0.60 & 0.25 & 0.25 \\
\hline Major, 2013 & $0.057-0.163$ & 0.50 & 0.25 & 1.00 \\
\hline
\end{tabular}

The Reynolds number Re [-] and the Weber number We [-] express the effect of friction and surface tension (Novak and Cabelka, 1981). Their effect on the value of the discharge coefficient is not occurred for water under common temperatures if $h \geq 0.06 \mathrm{~m}$ (Bos, 1989; ISO 3846, 2008), or $h \geq 0.05 \mathrm{~m}$ (Hager and Schwalt, 1994).

In weirs without lateral contraction $(B=b)$, the discharge coefficient does not depend on the relative width $h / b$ of the weir if $b \geq 0.3 \mathrm{~m}$ (ISO 3846, 2008).

The relative thickness $h / t$ of the weir has no effect on the value of the discharge coefficient in a range of $0.08 \leq h / t \leq 0.33$ (Singer, 1964) or $0.1 \leq h / t \leq 0.3$ (ISO 3846, 2008).
In the event that the relative equivalent roughness height $h / k$ is sufficiently large, the roughness corresponds to that of rolled sheet and the nappe is larger than the above-given minimum value, then the effect of the relative equivalent roughness height is negligible (Bos, 1989).

The aim of this paper is thus to determine the relationship $C_{d}=\mathrm{f}\{h / P\}$ in large range of relative height of the weir and to determine the limits of its applicability governed by the effect of surface tension and viscosity (specified by the value of the overflow head $h$ ) and the relative thickness $h / t$ of the weir.

\section{EXPERIMENT}

An experiment was carried out in the Laboratory of Water Management Research at the Institute of Water Structures at the Faculty of Civil Engineering at the Brno University of Technology (BUT). A rectangular weir made of polymethyl methacrylate with the same width as the channel of the flume $B=b=1.003 \mathrm{~m}$ and the thickness $t=0.500 \mathrm{~m}$ was mounted in a $12 \mathrm{~m}$ long flume with glass sidewalls. To achieve changes in the weir height $P=(0.250,0.151,0.103,0.077,0.052,0.032$ and 0.022$) \mathrm{m}$, a vertically adjustable bottom made of polyvinyl chloride, $4 \mathrm{~m}$ long, with a $1 \mathrm{~m}$ long inclined ramp was afore placed.

For measuring the discharge from $Q=0.01 \mathrm{~m}^{3} \cdot \mathrm{s}^{-1}$ to $0.13 \mathrm{~m}^{3} \cdot \mathrm{s}^{-1}$, a calibrated (by a volumetric method, uncertainty from $\pm 1.6 \%$ to $\pm 1.0 \%$ at $95 \%$ confidence interval) triangular sharp-crested weir with a $90^{\circ}$ notch was used. The measured stages were determined using changes in the discharge about $0.005 \mathrm{~m}^{3} \cdot \mathrm{s}^{-1}$ at a time. The measurement of the level $Z_{p}[\mathrm{~m}]$ of the weir crest and the level $Z_{h}[\mathrm{~m}]$ of the water surface at a distance of $3 h$ to $4 h$ (ISO 3846, 2008) was made using calibrated (by a digital length gauge) ultrasound probe PU 500, ELA (accuracy $\pm 0.2 \mathrm{~mm}$ ) which makes measurements at about $0.2 \mathrm{~s}$ intervals. The measurement of the water surface level was made over a time period of about 5 minutes to eliminate all pulsations of the position of the water surface. The average value obtained from measurement was further used for evaluation. Approach velocity distribution was lengthwise unchanged (Zachoval et al., 2012b) and the boundary layer was fully developed. The water temperature ranged from $17^{\circ} \mathrm{C}$ to $20^{\circ} \mathrm{C}$. In all cases, 175 measurements were made without aeration of the nappe. In all cases, the tailwater level was lower than the weir crest, thus the flow was unsubmerged (free).

\section{EVALUATION}

According to the Eq. (1), the discharge coefficient $C_{d}$ was calculated for the relevant discharge $Q$, overflow head $h=Z_{h}-Z_{p}$ and the designated weir height $P$. All values of the discharge coefficient $C_{d}$ were subsequently subjected to analysis for the effect of viscosity and surface tension expressed by the overflow head $h$. The functional relationship $C_{d}=\mathrm{f}\{h / P\}$ $(4 \mathrm{a}, 4 \mathrm{~b})$ was fitted only for a range of the relative weir thickness $0.12 \leq h / t \leq 0.30$ and the overflow head $h \geq 0.06 \mathrm{~m}$. Because of the trend, the resulting relationship is divided into two parts (Fig. 3):

$$
\begin{array}{ll}
\text { For } 0.20 \leq h / P<0.52 & C_{d}=0.845, \\
\text { and for } 0.52 \leq h / P<7.0 & C_{d}=0.038 \cdot \ln \frac{h}{P}+0.87,
\end{array}
$$

with the coefficient of determination $\mathrm{R}^{2}=0.98$. 


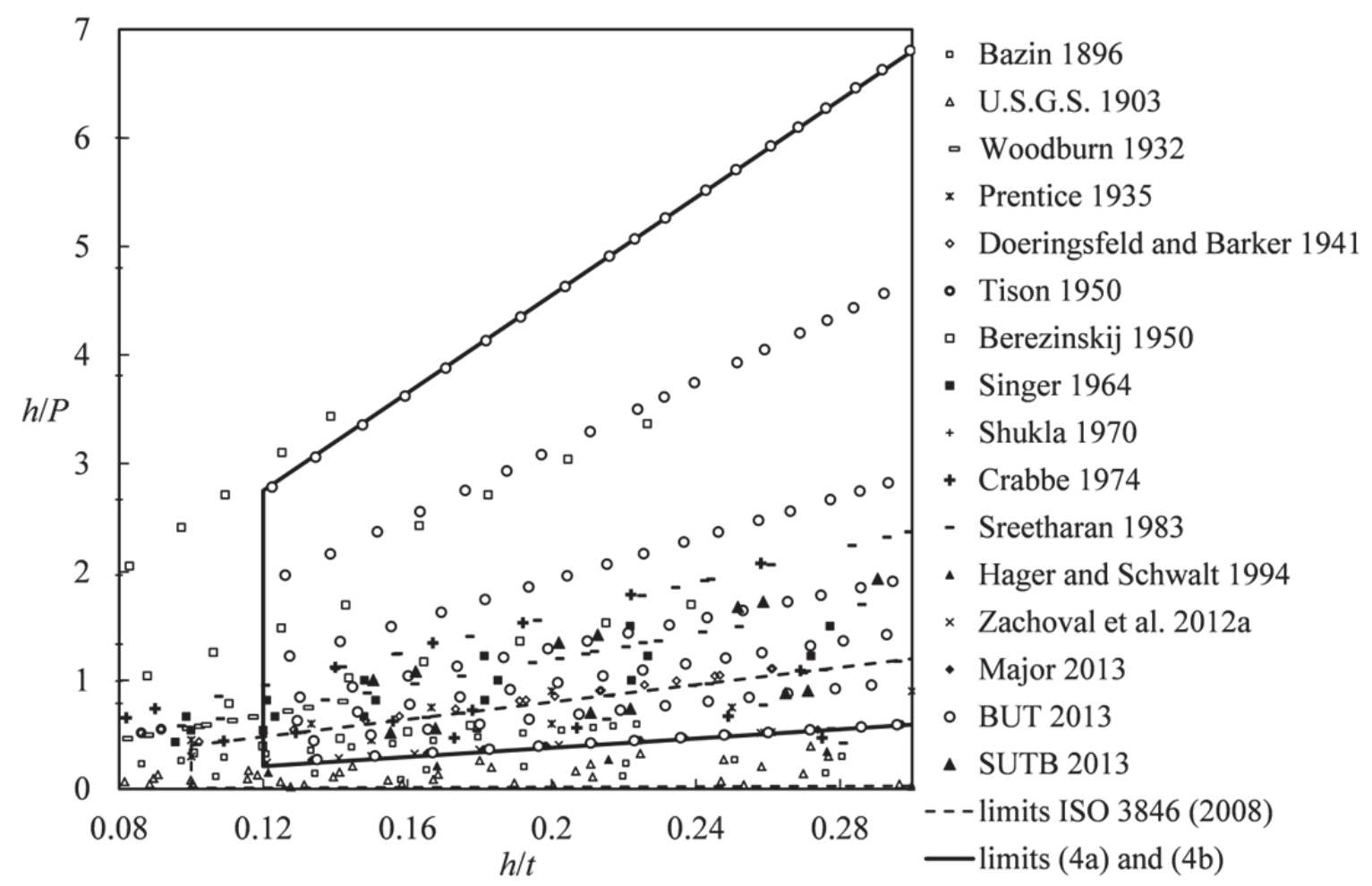

Fig. 1. Summary of measured data in a range $0.08 \leq h / t \leq 0.30$ and for $h \geq 0.06 \mathrm{~m}, b \geq 0.30 \mathrm{~m}$.

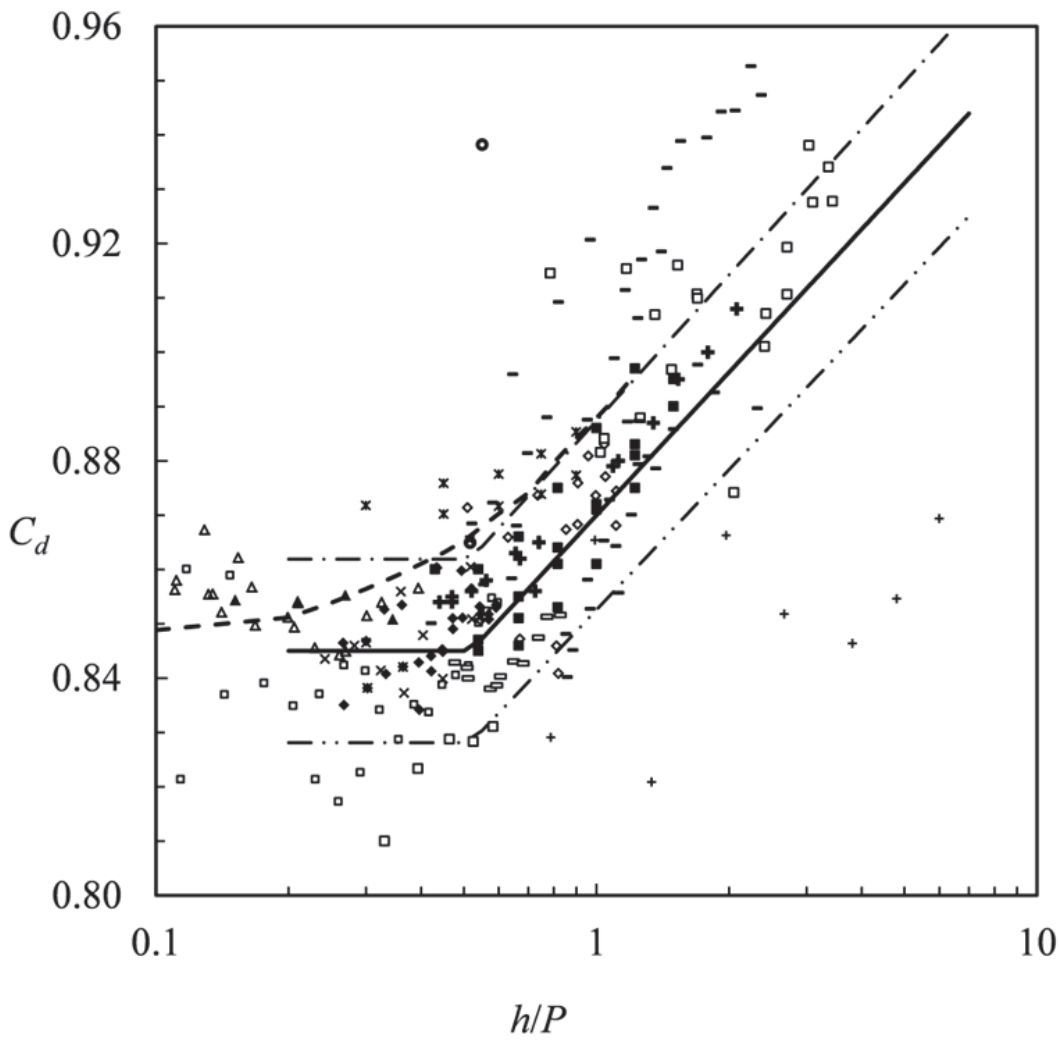

- Bazin 1896

$\triangle$ U.S.G.S. 1903

- Woodburn 1932

× Prentice 1935

- Doeringsfeld and Barker 1941

- Tison 1950

- Berezinskij 1950

- Singer 1964

+ Shukla 1970

+ Crabbe 1974

- Sreetharan 1983

- Hager and Schwalt 1994

- - ISO 38462008

$\times$ Zachoval et al. 2012a

- Major 2013

- eq. $4 \mathrm{a}$ and eq. $4 \mathrm{~b}$

$10-\cdot-+2 \%$, eq. $4 \mathrm{a}$ and eq. $4 \mathrm{~b}$

$-\cdots-2 \%$, eq. $4 \mathrm{a}$ and eq. $4 \mathrm{~b}$

Fig. 2. Discharge coefficients $C_{d}$ in relationship to the relative height $h / P$ of a rectangular sharp-edged broad-crested weir in a range $0.08 \leq h / t \leq 0.30$ and for $h \geq 0.06 \mathrm{~m}, b \geq 0.30 \mathrm{~m}$. 


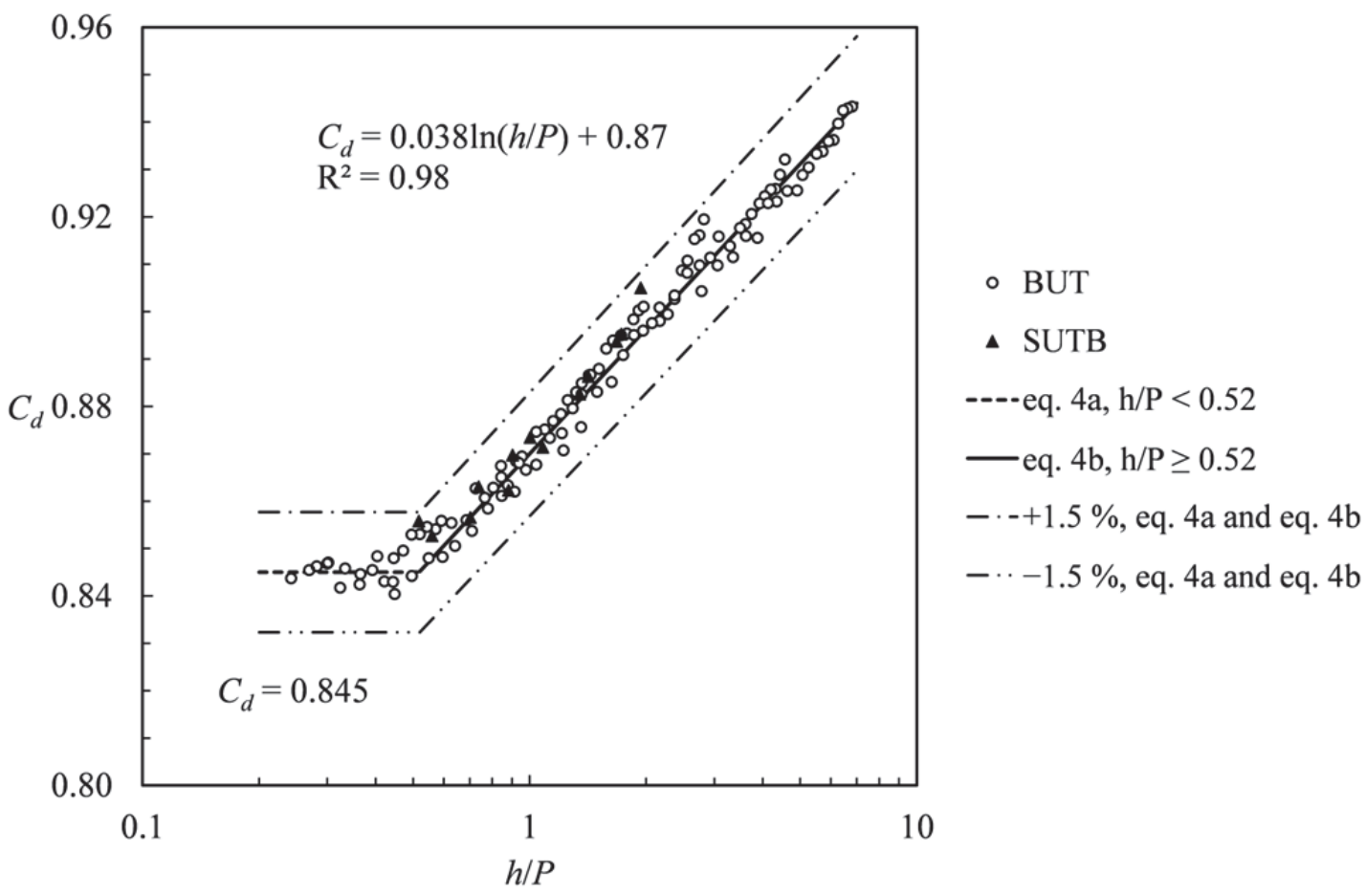

Fig. 3 Relationship between the discharge coefficient $C_{d}$ and the relative height $h / P$ of the weir for $h \geq 0.06 \mathrm{~m}$ and $0.12 \leq h / t \leq 0.30$.

The relative error $\delta=\Delta C_{d} / C_{d}$, which was displayed in Fig. 4 in relationship to the overflow head $h$, was calculated for all values of the discharge coefficient calculated from the measurement in range $0.1 \leq h / t \leq 0.3$. The pattern of the relationship displayed in Fig. 4 shows that the effect of viscosity and surface tension on the value of the discharge coefficient $C_{d}$ has no influence on the overflow head $h \geq 0.06 \mathrm{~m}$. This has confirmed the right choice of data selection for determining functional relationship $C_{d}=\mathrm{f}\{h / P\}(4 \mathrm{a}, 4 \mathrm{~b})$.

To analyze the effect of the relative thickness $h / t$ of the weir on the value of the discharge coefficient $C_{d}$, only the data with the overflow head $h \geq 0.06 \mathrm{~m}$ were used. These data served for calculating the relative error $\delta$, which is depicted in Fig. 5 in relationship to the relative thickness $h / t$ in the full range of the measured data. Fig. 5 shows that a certain relationship exists between the discharge coefficient $C_{d}$ and the relative thickness $h / t$ of the weir. Due to the small value of the relative error $\delta$, the effect of the relative thickness of the weir on the value of the discharge coefficient can be neglected in a range of $0.12 \leq h / t \leq 0.30$.

\section{VERIFICATION}

The above-given relationship (4a, 4b) for determining the discharge coefficient $C_{d}$ was subjected to verification that was carried out by the Department of Hydraulic Engineering at the Faculty of Civil Engineering at the Slovak University of Technology in Bratislava (SUTB).

A weir with the width $b=0.410 \mathrm{~m}$ and the thickness $t=0.500 \mathrm{~m}$ was constructed for verification. The heights $P=0.150 \mathrm{~m}$ and $0.075 \mathrm{~m}$ of the weir were made by changing the position of the upper bottom. The discharge $Q$ was determined using a calibrated electromagnetic flowmeter DN100, Endress + Hauser (uncertainty $\pm 0.2 \%$ at $95 \%$ confidence interval), and the level $Z_{p}$ of the weir, and the level $Z_{h}$ of the water surface in front of the weir were determined using a needle gauge (accuracy $\pm 0.1 \mathrm{~mm}$ ). In all cases, 22 measurements were carried out in a range of the discharges from $Q=0.0033 \mathrm{~m}^{3} \cdot \mathrm{s}^{-1}$ to $0.0469 \mathrm{~m}^{3} \cdot \mathrm{s}^{-1}$. The flow was unsubmerged.

The measured data served for calculating the discharge coefficient $C_{d}$ according to the Eq. (1). The calculated values of the discharge coefficient were plotted in the graph in Fig. 3 for $h \geq 0.06 \mathrm{~m}$ and $0.15 \leq h / t \leq 0.29$ (13 points) together with the verified relationship. Fig. 3 shows that the newly determined relationship is verified in a range of $0.5<h / P<2.0$ with a deviation within $\pm 1.5 \%$.

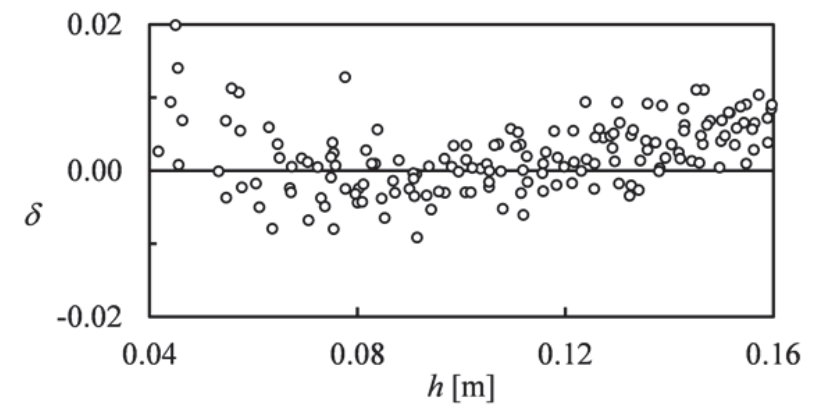

Fig. 4. Relative error $\delta$ of the discharge coefficient $C_{d}$ in relationship to the overflow head $h$.

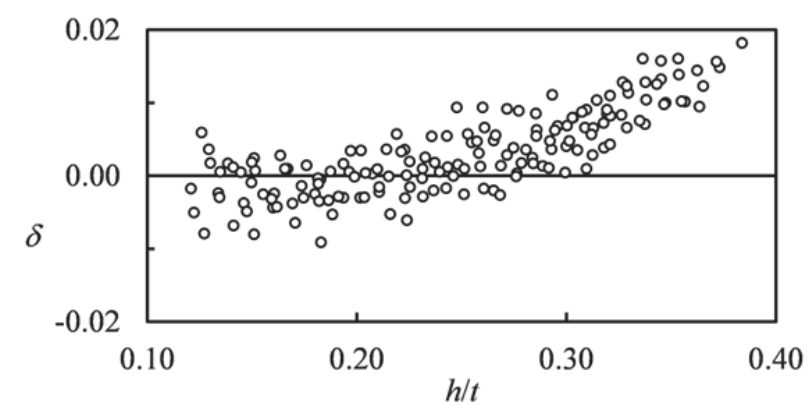

Fig. 5. Relative error $\delta$ of the discharge coefficient $C_{d}$ in relationship to the relative thickness $h / t$ of the weir for $h \geq 0.06 \mathrm{~m}$. 


\section{CONCLUSIONS}

The new relationship between the discharge coefficient $C_{d}$ and $h / P$ was determined for the rectangular sharp-edged broadcrested weir in a range of relative thickness $0.12 \leq h / t \leq 0.30$ and newly in a large range of relative weir height (extremely $0.20<h / P<7.0)$. The knowledge of $C_{d}$ for high values of $h / P$ allows extend the application possibilities of relatively low weirs.

The relationship was divided into two parts (Fig. 3): for $0.20 \leq h / P<0.52$, the discharge coefficient is a constant function $C_{d}=0.845(4 \mathrm{a})$; and for the values $0.52 \leq h / P<7.0$, the discharge coefficient depends on the relative height of the weir according to the Eq. (4b), i.e. $C_{d}=0.038 \cdot \ln (h / P)+0.87$. The application limits are shown in the Fig. 1.

The Eqs. (4a) and (4b) were verified by an independent laboratory SUTB with relative error $\pm 1.5 \%$ in a range of $0.5<h / P<2$ (Fig. 3). Measurements provided by U.S.G.S (1903) (in Horton, 1907), Woodburn (1932), Singer (1964), Crabbe (1974), Hager and Schwalt (1994), Zachoval et al. (2012a) and Major (2013) gives similar values with relative error $\pm 2 \%$ in a range $0.2<h / P<2$ (Fig. 2). Standard ISO 3846 (2008) recommends similar values of $C_{d}$ only for low values of $h / P$; for $0.4<h / P<1.2$ recommends about $2 \%$ higher values; and for $h / P>1.6$ there are no recommended data.

Friction and surface tension have no effect (with an relative error within $\pm 1 \%$ ) on the value of the discharge coefficient $C_{d}$ during water overflow under common temperatures with the overflow head $h \geq 0.06 \mathrm{~m}$. Same limit gives ISO 3846 (2008). The effect of friction and surface tension is shown in Fig. 4 for other overflow heads.

The discharge coefficient $C_{d}$ in a range of $0.12 \leq h / t \leq 0.30$ depends dominantly on the relative height $h / P$ of the weir. The significance of the relationship to the relative thickness $h / t$ of the weir is within $\pm 1 \%$, therefore it can be neglected (Fig. 5).

Acknowledgement. Thanks are due to the project GA103/09/0977 - Experimental and numerical modelling of turbulent flow with massive separation and to the project FAST-S-12-8 - Discharge characteristics of a rectangular broad-crested weir.

\section{REFERENCES}

Berezinskij, A.P., 1950. Carrying capacity of the broad-crested weir. Vodgeo, Moscow. (in Russian.)

Bos, M.G., 1989. Discharge measurement structures. Third revised edition. Publication 20. ILRI, Wageningen.

Crabbe, A.D., 1974. Some hydraulic features of the squareedged broad-crested weir. Water and Water Eng., 78, 10, 354-358.

Doeringsfeld, H.A., Barker, C.L., 1941. Pressure-momentum theory applied to the broad-crested weir. Trans. ASCE, 106, 1, 934-946.

Goodarzi, E., Farhoudi, J., Shokri, N., 2012. Flow characteristics of rectangular broad-crested weirs with sloped upstream face. J. Hydrol. Hydromech., 60, 2, 87-100.

Govinda Rao, N.S., Muralidhar, D., 1963. Discharge characteristics of weirs of finite-crest width. La Houille Blanche, 18, $5,537-545$.
Hager, W.H., Schwalt, M., 1994. Broad-crested weir. J. Irrig. Drain. Eng., 120, 1, 13-26.

Harrison, A.J.M., 1967. The streamlined broad-crested weir. Proc. ICE Proc., 38, 4, 657-678.

Horton, R.E., 1907. Weir experiments, coefficients, and formulas. U.S.G.S., Washington, USA.

ISO 3846, 2008. Liquid flow measurement in open channels by weirs and flumes. Rectangular broad-crested weirs.

Johnson, M.C., 2000. Discharge coefficient analysis for flattopped and sharp-crested weirs. J. Irrig. Sci., 19, 3, 133-137.

Major, J., 2013. Influence of upstream face inclination of broad-crested weir on discharge coefficient. Bachelor thesis. Brno University of Technology, Brno, Czech Republic. (in Czech.)

Moss, W.D., 1972. Flow separation at the upstream edge of square-edged broad-crested weir. J. Fluid Mech., 52, 2, 307320.

Novak, P., Cabelka, J., 1981. Models in hydraulic engineering. Physical principles and design applications. Pitman Advanced Publishing Program, London, United Kingdom.

Shukla, M.K., 1970. Characteristics of flow over weirs of finite crest width. Master of Science thesis. Indian Institute of Technology Kanpur, Kanpur, Uttar Pradesh, India.

Singer, J., 1964. Square-edged broad-crested weir as a flow measurement device. Water and Water Eng., 28, 820, 229235.

Sreetharan, P.M., 1983. Analytical and experimental investigation of flow measurement by long-based weirs in the rectilinear and curvilinear ranges. $\mathrm{PhD}$ thesis. The Hatfield Polytechnic, Hatfield, Hertfordshire, England.

Stevens, J.C., Wilm, H.G., Nelidov, I.M., Hackney, J.W., Prentice, T.H., Bakhmeteff, B.A., Curtis, D.D., Rohwer, C., Hedberg, J., Doeringsfeld, H.A., Barker, C.L., 1941. Discussion of Pressure-momentum theory applied to the broadcrested weir. Trans. ASCE, 106, 1, 947-967.

Tim, U.S., 1986. Characteristics of some hydraulics structures used for flow control and measurement in open channels. $\mathrm{PhD}$ thesis. Concordia University, Montreal, Quebec, Canada.

Tison, L.J., 1950. Broadcrested weir. La Houille Blanche, 4, 426-439. (in French.)

Tracy, H.J., 1957. Discharge Characteristics of Broad-Crested Weirs. U.S. Department of Interior, Geological Survey Circular 397.

Shaw, T.L., Wakhlu, O.N., Salih, A.M.A., Francis, J.R.D., 1972. Discussion of The rounding of the upstream edge of a broad-crested weir. Proc. ICE Proc., 53, 1, 117-121.

Woodburn, J.G., 1932. Tests of Broad-Crested Weirs. Trans. ASCE, 1797, 387-416.

Zachoval, Z., Mistrová, I., Roušar, L., Šulc, J., Zubík, P., 2012a. Zone of flow separation at the upstream edge of a rectangular broad-crested weir. J. Hydrol. Hydromech., 60, 4, 288-298.

Zachoval, Z., Pařílková, J., Roušar, L., 2012b. Velocity measurements in front of rectangular broad-crested weir. Proc. 26th Symp. Anemometry, pp. 113-119. (in Czech.)

Received 5 November 2013 Accepted 29 January 2014 